\title{
AN OPERATION FOR HIATUS HERNIA WITH SHORT OESOPHAGUS
}

\author{
BY \\ J. LEIGH COLLIS \\ From the Queen Elizabeth Hospital, Birmingham
}

(RECEIVED FOR PUBLICATION MARCH 29, 1957)

The patient with a hiatus hernia and a markedly short oesophagus presents a problem for which there is not at present a generally accepted line of treatment. There are gross macroscopic changes in the oesophagus and they tend to give rise to severe pain and dysphagia. The shortening of the oesophagus makes the problem unsuitable for treatment by the standard operations for hiatus hernia, while some of the suggested treatments, such as oesophago-jejunostomy, are so formidable that they are unsuitable for the frail and often aged subjects.

Anatomical and physiological investigations which were published in 1954 led me to refashion my operative technique for the problem of hiatus hernia generally (Collis, Kelly, and Wiley, 1954). These investigations and the experience with the modified technique demonstrated certain points which seemed to have a special bearing on the difficult problem of the patient with a short oesophagus.

Evidence was put forward in that paper to show that some infants with a hiatus hernia lose their symptoms before they lose the radiologically demonstrable hiatus hernia. It was suggested that this was due to the development of tone in the crural fibres so that gross reflux from the stomach below the diaphragm is controlled. The small amount of reflux which remains is sufficient to allow fluid to enter the gastric pouch above the diaphragm, but the force of the reflux is weak and can be controlled by the sphincter action at the cardia. If these children are followed up, it will be seen that further complete power to control reflux at the hiatus will usually be developed and when this is effected the hernia will in most cases remain reduced. This reduction does not always take place, but if the control at the hiatus is good the condition is very difficult to demonstrate radiologically and can only be shown at oesophagoscopy. This state of affairs is often referred to as a gastric-lined oesophagus.
This situation holds dangers for the patients in later life, but is compatible with many years of either symptom-free existence or a state of only trivial trouble. It seemed reasonable to wonder if something along similar lines could not be arranged for patients with established short oesophagus and free reflux.

The essential part of the refashioned operation described in 1954 was that an acute angle of implantation between the stomach and the oesophagus should be formed. This is effected by suturing the two limbs of the right crus above and in front of the oesophagus. As a result of this, the point around which the oesophago-gastric junction angulates is lowered, with the effect that the angle automatically becomes more acute. The operative technique was fully described and it is only necessary to add that it has continued to give good results.

The point of particular importance here is that the operation was used on some cases in which the oesophagus was short, and as a result the cardia could not be returned to the hiatus. The results in this group were not perfect, but it was clear that in many cases reflux could be controlled and symptomatic relief given. The weakness of this procedure was a technical one, in that there was too much bulk tissue occupying the oesophageal hiatus, so that a satisfactory angle between the stomach above the diaphragm and that below could not be produced.

The suggestion that is now being made is that gastric tissue can be used to form the connecting tube between the lower end of the short oesophagus and the main body of the stomach within the abdomen. In view of the possible disadvantages of the use of this tissue it is desirable to have a clear knowledge of the physiological secretions of the part involved. In 1934 Berger described a careful study of the distribution of the parietal cells of the stomach which are the 


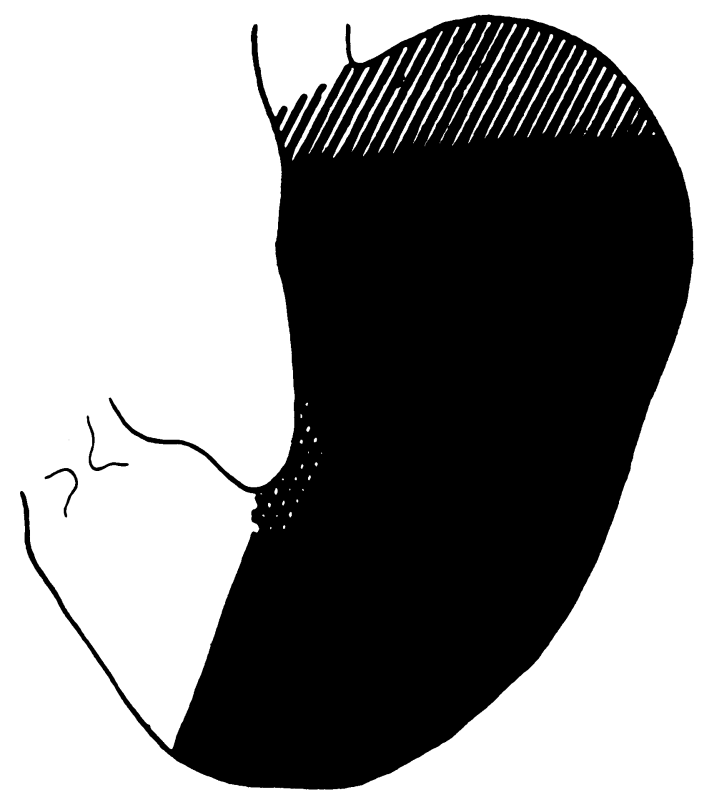

FIG. 1. - This diagram is taken from the paper by Berger. The main body of the stomach is shaded black and is rich in parietal cells which produce $\mathrm{HCl}$. Relative to this the shaded area at the cardia only has $50 \%$ of the parietal cells.

main source of hydrochloric acid. Fig. 1 is reproduced from Berger's paper to show the arrangement. From this it will be seen that the area adjacent to the cardia has only a limited supply but that most of the lesser curve is well supplied. A series of sections was made from gastric tissue to confirm this statement.

Another important work on this subject was produced by Billenkamp in 1929. He made a special study of the magenstrasse in 15 different species, including man, and he found that the mucosa of this area was thinner in man than other parts of the stomach and that it was practically devoid of peptic glands.

It would seem that the area of the cardia and lesser curve has a definite power of producing acid but that it is deficient in its power to produce pepsin.

\section{General Plan of Operation}

In view of the experience from congenital defects in this area and the work of Berger (1934) and Billenkamp (1929), it seems reasonable to put forward a plan for using a gastric connecting link between the short oesophagus above and the main body of the stomach below the diaphragm, provided that certain precautions are taken.
First, it is necessary to use only gastric tissue $\stackrel{\overrightarrow{\vec{F}}}{\vec{\rho}}$ of the magenstrasse. Secondly, an effective valvec action must be obtained so that reflux is prevented $\frac{\bar{\sigma}}{\overline{0}}$ from the main body of the stomach into the con- $\frac{5}{2}$ necting link and oesophagus above. Thirdly. it $\mathbb{Q}$ seems desirable that as narrow a tube of stomach as possible is used so that the amount of gastric $\vec{O}$ secretion should be minimal.

\section{TEChNique OF OPERATION}

The patient is placed on his right side with his whole body rotated a little backwards. An $\vec{N}$ abdomino-thoracic incision is made from the umbilicus to the edge of the trapzzius along the $\vec{\infty}$ line of the seventh or eighth rib The chesto and abdomen are opened by resection of one or $\rightarrow$ other of these ribs. It is found desirable to $s$ remove a segment of the costal margin. The $\mathbb{D}$ incision in the diaphragm should be made as far $\stackrel{\mathbb{D}}{ }$ laterally as possible so as to minimize the number of filaments of the phrenic nerve which are cut. 믐 For the same reason it should only be taken to a $\vec{c}$ point half an inch short of the central tendon. जy This is important to ensure generally good function in the diaphragm after this operation. A smosislo amount of lateral weakness is not a disadvanta

The mediastinum is dissected so as to demot strate the short oesophagus and stomach pouch. 음 In some cases it will be found that so much extra length of oesophagus can be obtained by this $\overrightarrow{\overline{0}}$ dissection to effect a standard plastic repair. When this cannot be achieved the gastric pouch is carefully cleared of vascular attachments so that it surface is smooth and clean. In order to do this it is useful to be able to inspect the stomach from below and to bring extra stomach up into the chest.

When this stage is completed the anaesthetist $\frac{0}{3}$ passes a No. 9 (English gauge) stomach tube from: the mouth into the intra-abdominal part of the을 stomach. Parker-Kerr clamps are then applied as shown in Fig. 3. The distal ends of these clamps are brought as close as possible to the small stomach tube and lesser curve. The object of this is to make certain that the tube of stomach at this point will be as narrow as possible. The stomach is incised between the clamps and the free cuffo sewn up before the clamps are removed.

After removing the clamps the suture line is invaginated. The position now is as shown ine Fig. 4. The part of the stomach pouch to the left is now returned below the diaphragm and has the? effect of enlarging the fundus. Above the diaphragm a portion of the pouch remains which willo from now on be referred to as the " connecting tube." 


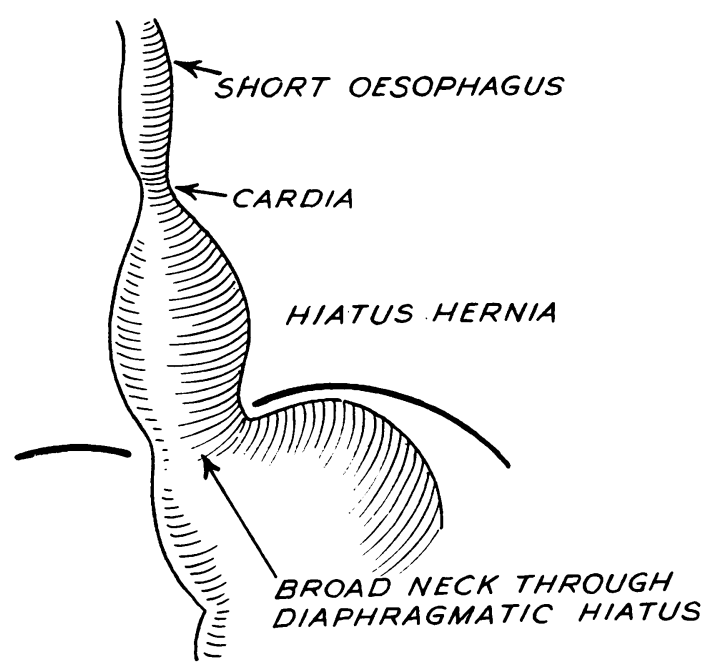

FIG. 2.-This is a diagrammatic representation of the condition under consideration. A hiatus hernia is present with a short oesophagus. A broad neck of gastric tissue occupies the diaphragmatic hiatus.

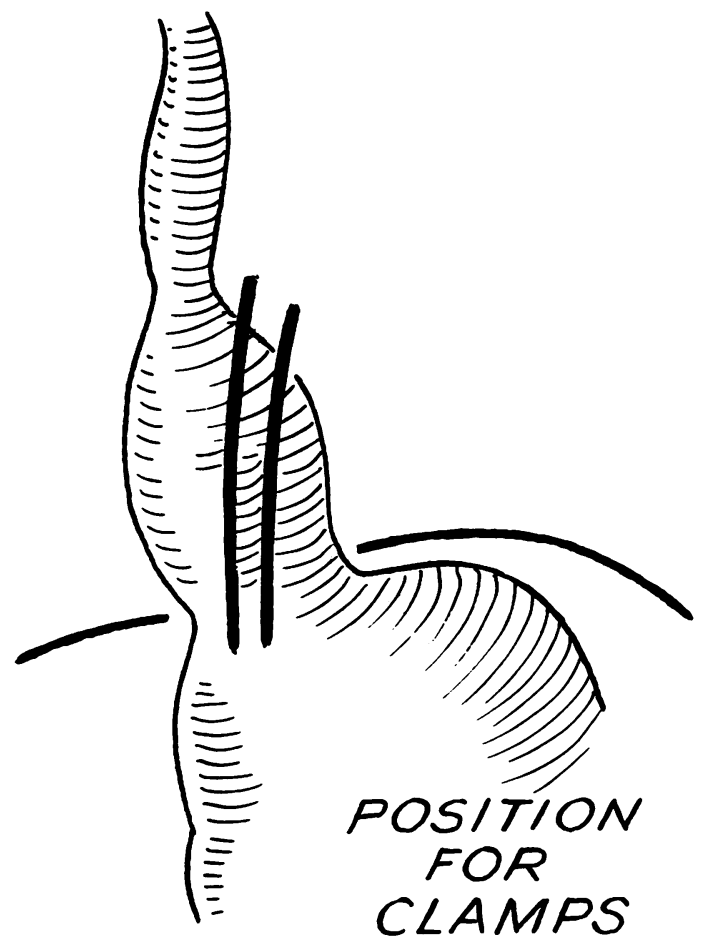

FIG. 3.-The parallel dark lines show the position in which the clamps are placed. The lower end of the clamp is brought as close as possible to the lesser curve. When the clamps are on, the gastric pouch is divided by them into two halves.

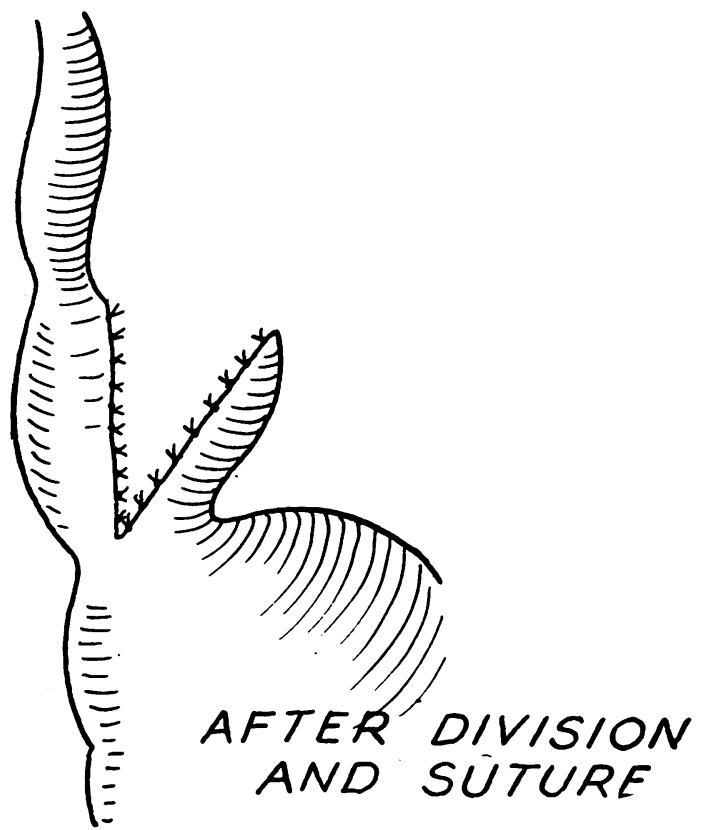

Fig. 4. - This shows the position after the clamps have been removed and the stomach incised. The pouch of the hiatus hernia has now been divided into two parts. First there is the part along the lesser curve which is the connecting tube, and secondly there is the part to the left which is going to be given back to the fundus.

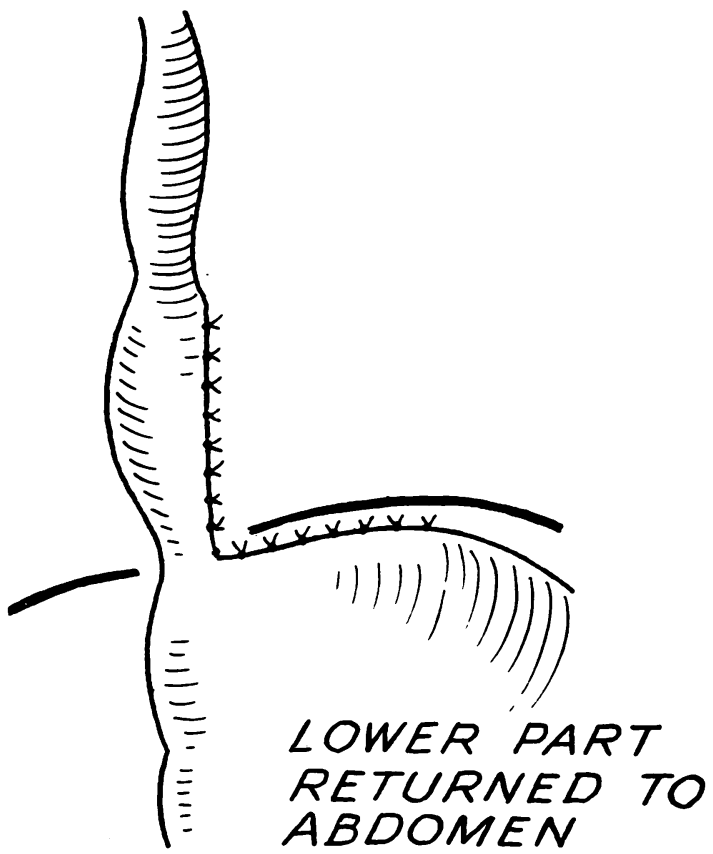

FIG. 5.-The oesophagus and the connecting tube only remain above the diaphragm. Only a narrow neck of gastric tissue is now in the diaphragmatic hiatus. Around this narrow tube a satisfactory plastic repair of the fibres of the right crus can be performed. 
The last phase of the operation is the plastic repair as described earlier in Thorax (Collis, Kelly, and Wiley, 1954). It is done from below the diaphragm. The under surface of the fibres of the right crus are dissected clean of everything except peritoneum, which is carefully preserved. The limbs of the right crus are now sutured together above and in front of the connecting tube. This produces an acute angle between the connecting tube and the main body of the stomach. As the diaphragm is closed the stomach is included in two of the stitches in order to retain the connecting tube and oesophagus in position. The chest and abdomen are closed with intercostal drainage for 48 hours.

\section{RESUlts}

Fig. 6 is a typical example of the type of case for which this operation has been done. Fig. 7 shows the same case after gastroplasty. The connecting tube can be seen. A good angle of implantation into the stomach had been produced and no regurgitation could be induced at barium swallow examination.

The operation has been carried out on nine patients between April, 1955, and September, 1956. Seven were women and two were men. Their ages were between 50 and 70 in seven of the patients. The other two were aged 31 and 37 years. All had gross symptoms. Dysphagia was prominent in seven patients and one had had many oesophagoscopies for dilatation. At oesophagoscopy oesophagitis was marked in all cases, with ulceration noted in five. The oesophageal length was between 29 and $34 \mathrm{~cm}$. It is to be noted that the grossest forms of short oesophagus have not been treated this way so far.

After operation one of the patients who was apparently making good progress died with a coronary thrombosis. He was aged 67 . In the first case, in a woman aged 31 , reflux was not satisfactorily controlled, and although she is improved her condition is not considered satisfactory. The post-operative result in the other seven is excellent. A check barium swallow has been done in all of these between eight and 12 months from operation and in six no reflux could be produced. In one only slight reflux occurred. At the same period after operation these patients were also checked by oesophagoscopy and the complete absence of oesophagitis and stricture was noted. No patient has required post-operative oesophagoscopy and dilatation. This is in spite of the previous dilatations required in one case. It is to be noted that in the immediate post-operative period marked dysphagia was present in most patients and that

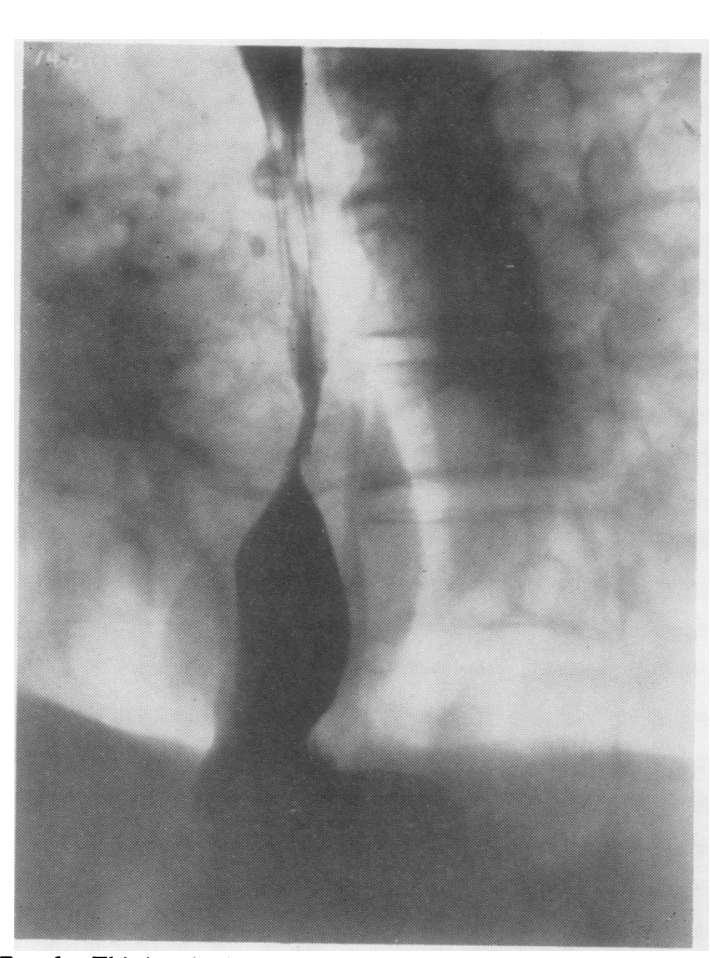

FIG. 6.-This is a barium swallow film to show the type of case for which the operation has been done, i.e., an irreducible hiats hernia with a short oesophagus. There is marked narrowinget the cardia and the patient had gross dysphagia.

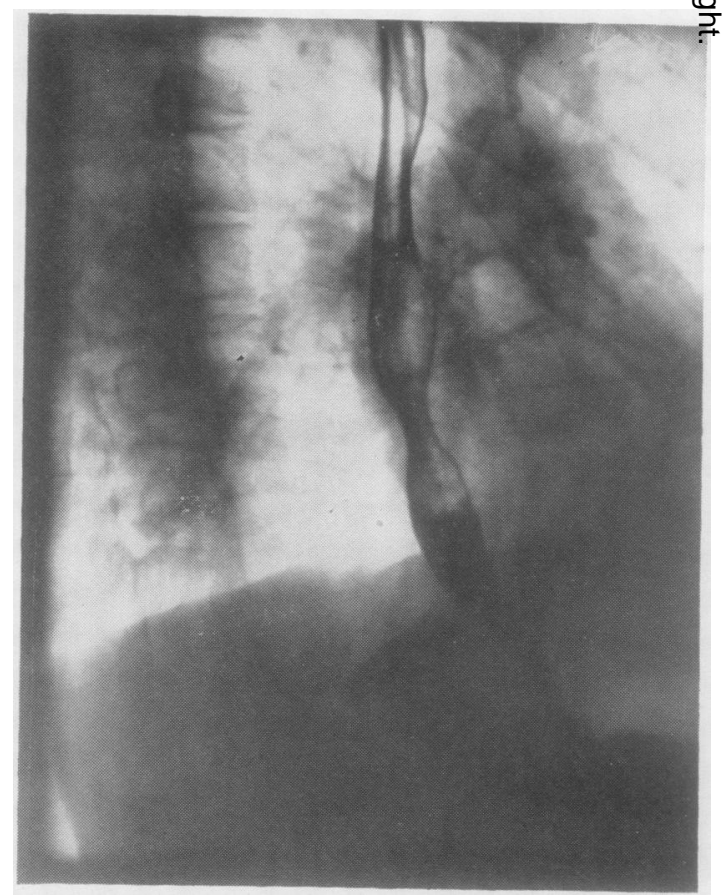

FIG. 7.-This is the same patient as shown in Fig. 6. A gastroplasty has now been performed. The connecting tube can clearly be seen with the cardia in about the same position as before operation. It is to be noted that the narrowing at the cardia has gone and this is in spite of no post-operative dilatation. 

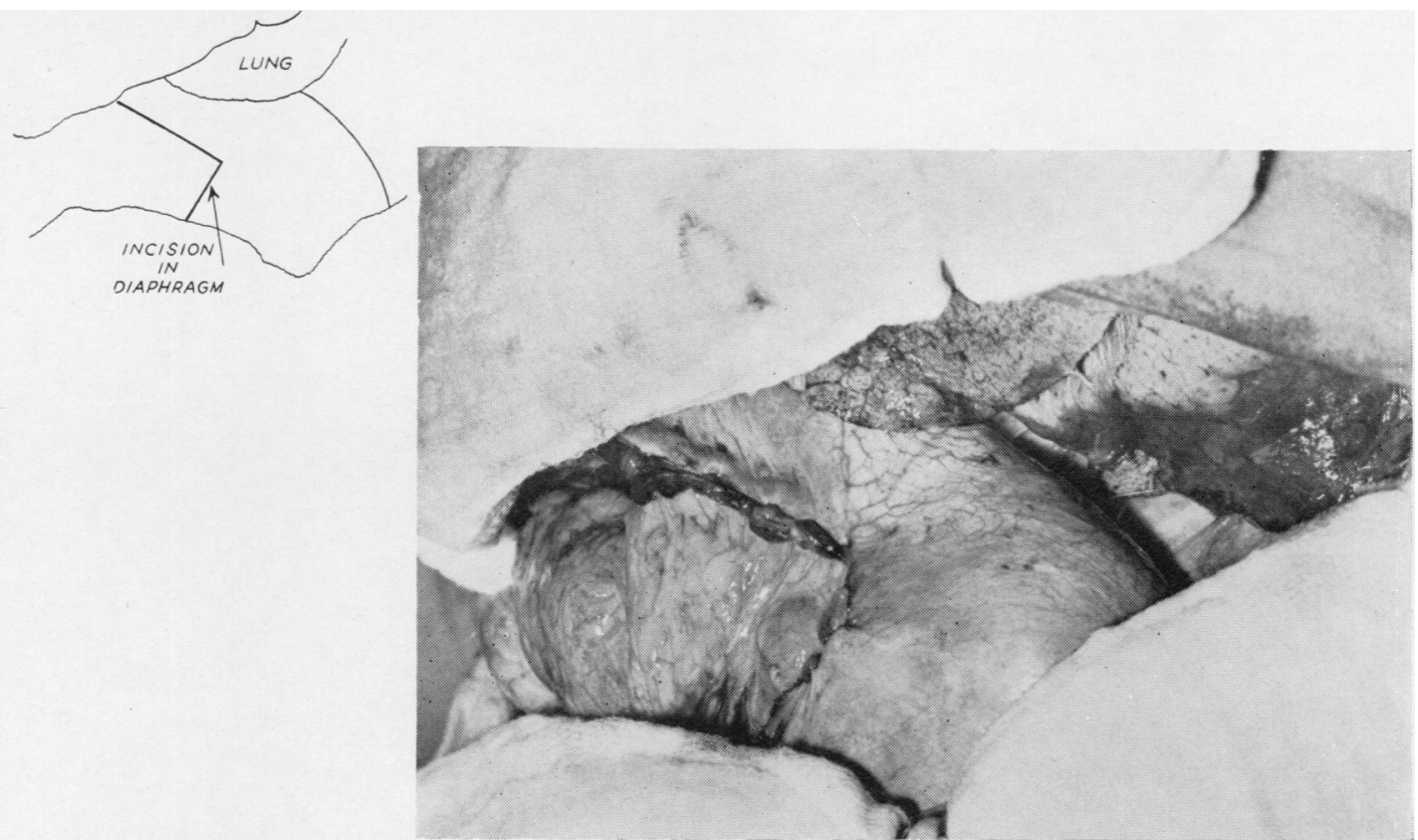

FIG. 8. -The incision has been made and the wound opened. The incision in the diaphragm is shown, and it will be seen that it stops short of the edge of the central tendon.
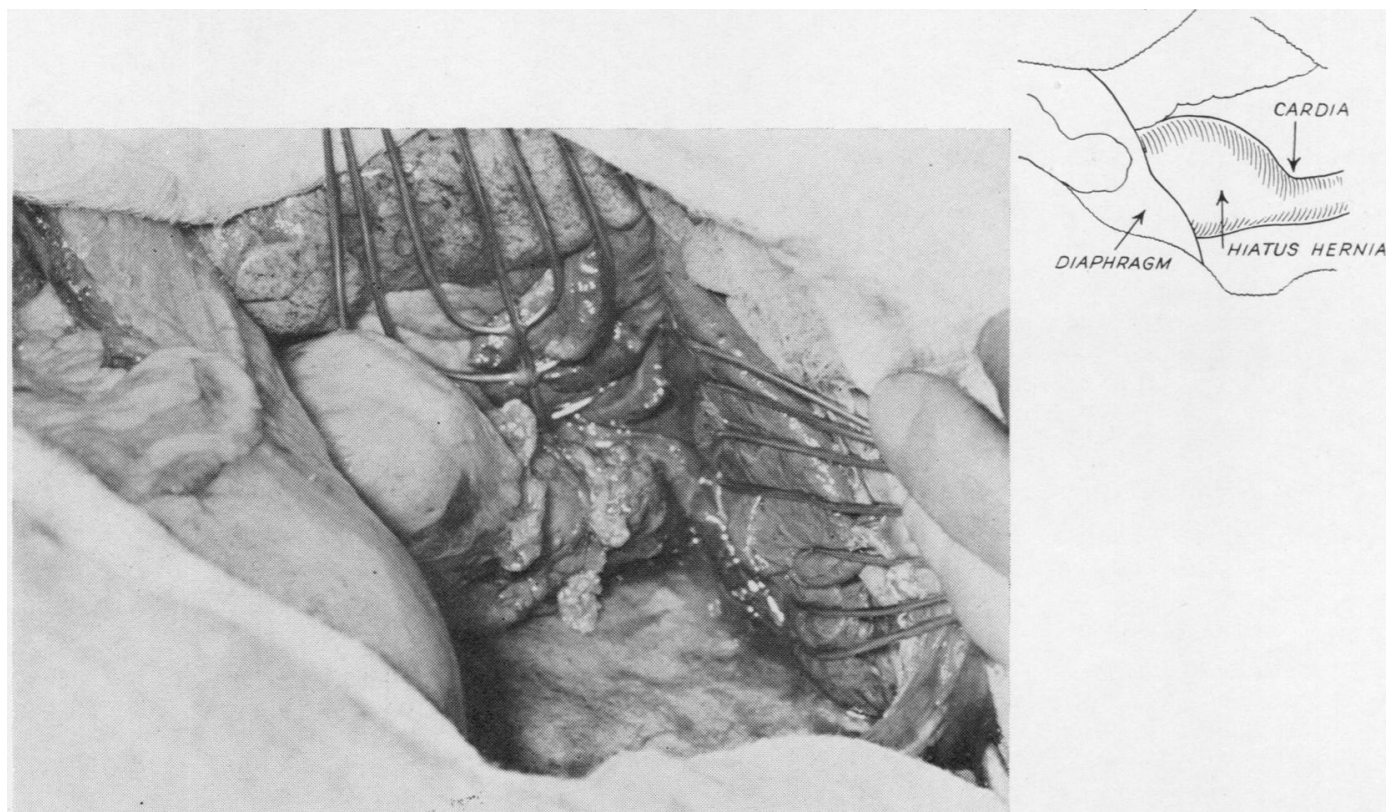

Fig. 9. -The mediastinum has now been dissected to show the stomach pouch and cardia. 

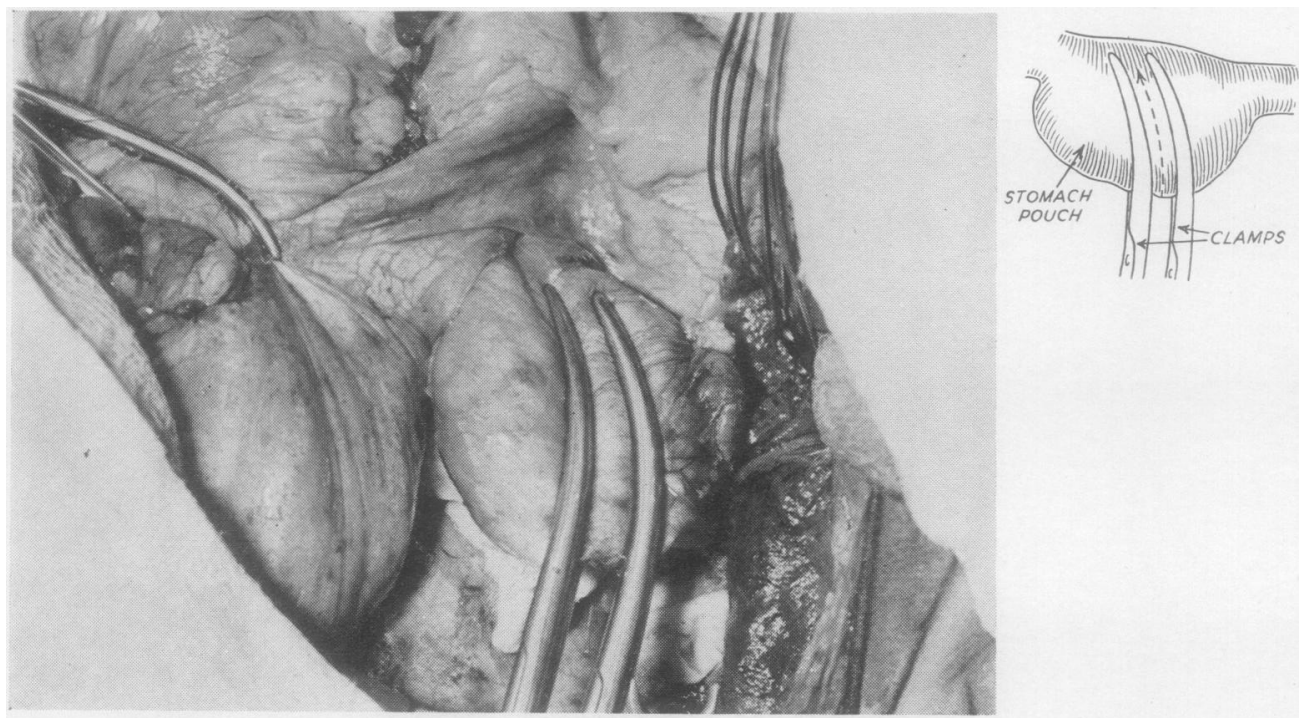

Fig. 10.-The smallstomach tube is now in position and the Parker-Kerr clamps have been placed on the stomach pouch. The tips of these clamps are brought as close as possible to the lesser curve.

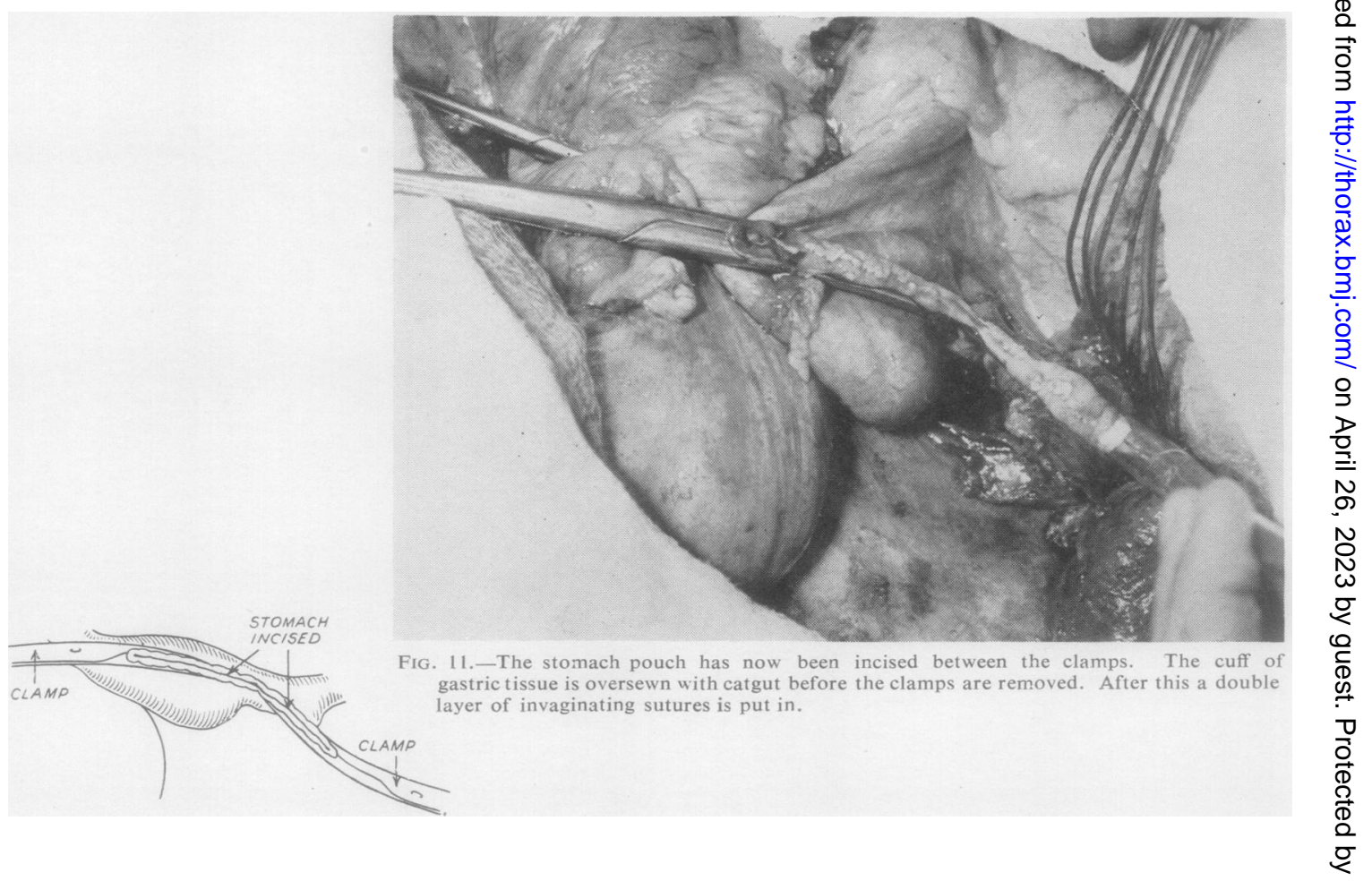


FIG. 12.-The clamps have been removed and the double layer of invaginating sutures has been inserted. The gastric pouch has now been divided into two parts. To the right is the connecting tube and to the left is the part which will be returned below the diaphragm to add to the size of the fundus.

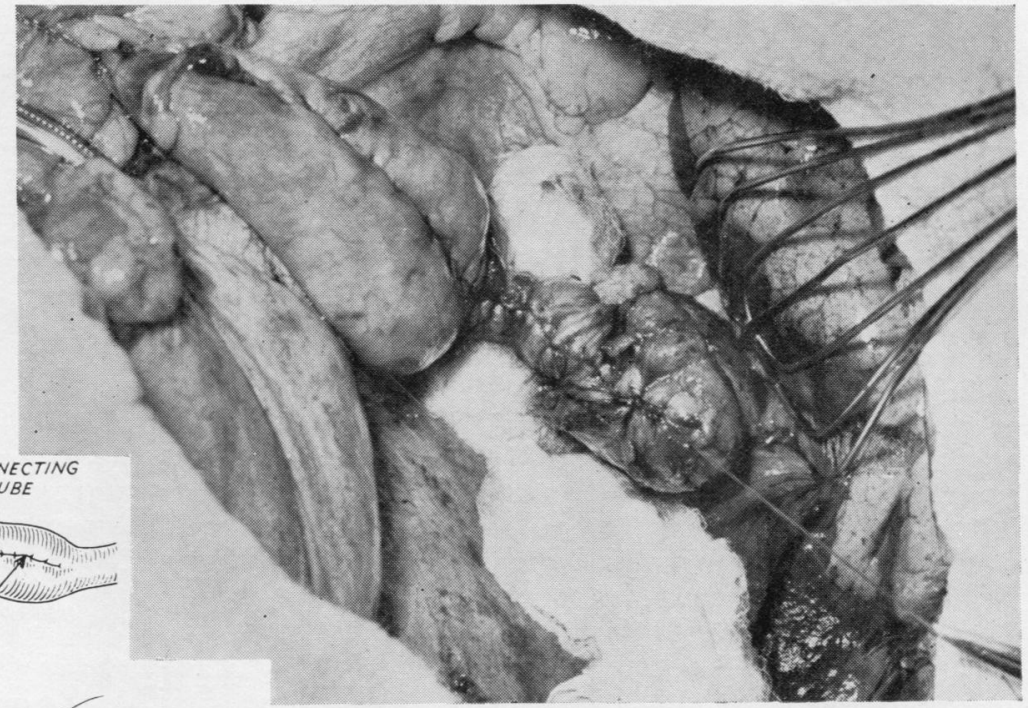

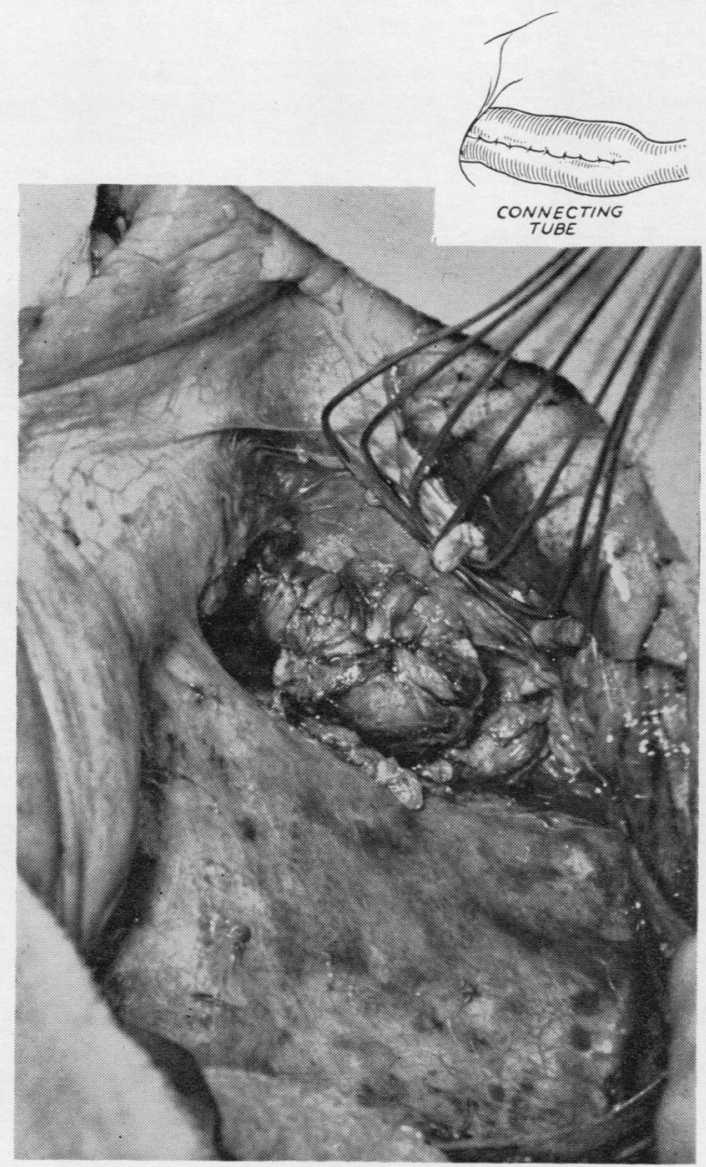

Fig.13.-Only the connecting tube now remains above the diaphragm. It lies in the mediastinum and gives extra length to the oesophagus so that the plastic repair at the hiatus will be able to be done without tension.
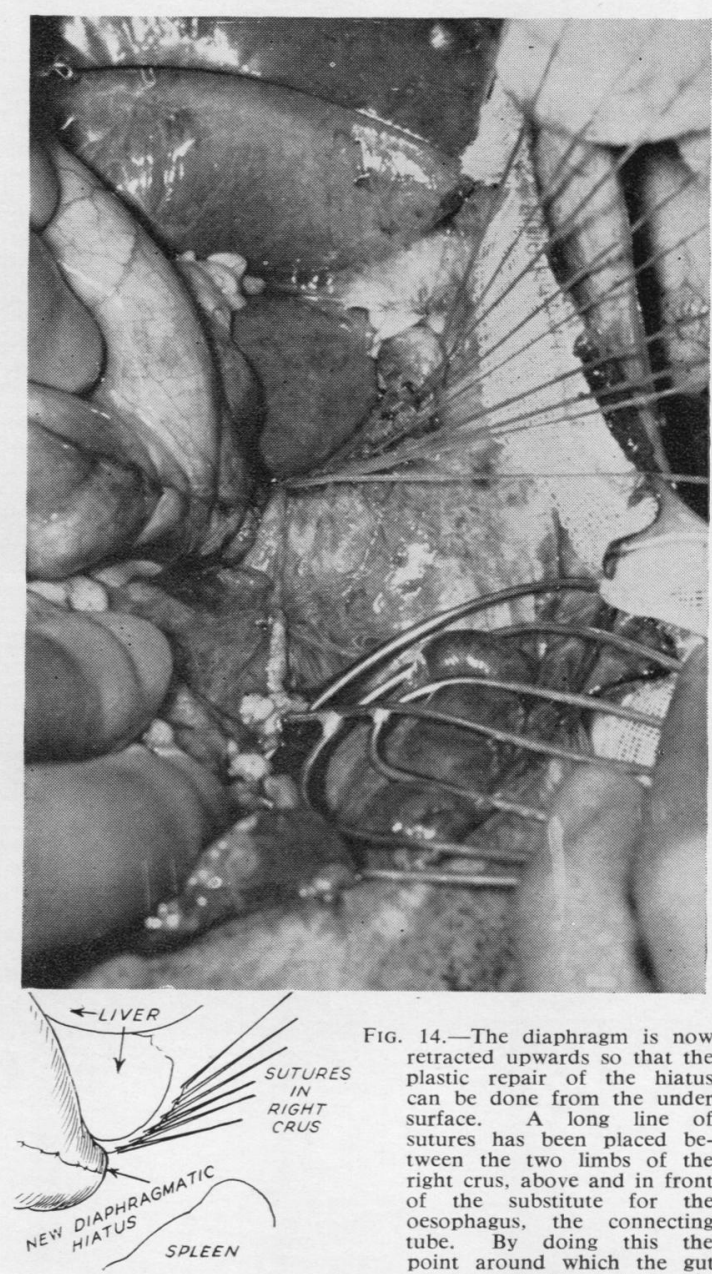

FIG. 14.-The diaphragm is now retracted upwards so that the plastic repair of the hiatus can be done from the under surface. A long line of sutures has been placed be tween the two limbs of the right crus, above and in fron of the substitute for the oesophagus, the connecting tube. By doing this the point around which the gut angulates is lowered by the suture line. The fundus with suture line. The fundus with half of the gastric pouch added to it is seen on the 
it often continued for three weeks from operation. Some slight difficulty in swallowing was often present after this, but in all cases it steadily improved. Some degree of immediate postoperative dysphagia is regarded as desirable and it is felt that if it is not present the operation has not been done properly.

Only one major post-operative complication occurred. This was a left subphrenic abscess with a leak from the suture line. The whole condition subsided spontaneously with drainage of the pus.

The improvement of the general health of these patients has been remarkable and has resulted in their suffering less from other coexistent diseases. One patient had suffered for many years from narcolepsy and another from Parkinsonism. The symptoms of both conditions have become remarkably less.

\section{CONCLUSIONS}

The operation, which is called gastroplasty, is of considerable magnitude, but is still much smaller than oesophago-jejunostomy, and is well tolerated even by old and weak patients. It leaves the digestive arrangements near normal and there is no problem afterwards with nutrition. Excellent results have been obtained in seven patients, but the unsatisfactory state in the first case must be taken as a warning of the need to narrow the connecting tube sufficiently so that a really good angle of implantation can be obtained. The procedure has not been used on the very short oesophagi where the cardia is in the region of the aortic arch or above. The reason for this is conservatism, and it is felt that results justify its use for these also.
Attention has been drawn to the spontaneous relief of dysphagia after this operation. By this it is intended to suggest that many strictures which are generally believed to be fibrous are in fact mainly produced by reflex spasm. In these cases when the irritation of reflux has been removed? and the oesophagitis has subsided the dysphagia will no longer be present. While putting this forward as an observed fact it is fully appreciated that in some strictures fibrous change is presen and it is anticipated that oesophagoscopy may well $\vec{k}$ have to be done for dilatation in some cases in the future.

\section{SUMMARY}

An operation is described for the condition of hiatus hernia with short oesophagus.

The method involves the use of a small portion of stomach as a connecting link between the oeso $\frac{\mathbb{D}}{3}$ phagus above and the main body of the stomacto below the diaphragm.

The results of the use of the procedure in nines patients are described.

The operation is referred to as a gastroplasty

I am particularly indebted to Dr. J. C. A. Raisôn of the Thoracic Surgical Unit, Warwick, for helpJin this work. My thanks are also due to Mr. L. Dee? clinical photographer to the Queen Elizabeth Hospital, Birmingham.

\section{REFERENCES}

Berger, E. H. (1934). Amer. J. Anat., 54, 87. Billenkamp, H. (1929). Beitr. path. Anat., 82, 475. Collis, J. L., Kelly, T. D., and Wiley, A. M. (1954). Thorax, 9, 17 